\title{
Trilingual Internet Use, Identity, and Acculturation among Young Minority Language Speakers: Some Data from Transylvania and Finland $^{1}$
}

\author{
László VINCZE \\ Swedish School of Social Science, University of Helsinki \\ e-mail: laszlo.vincze@helsinki.fi \\ Tom MORING \\ Swedish School of Social Science, University of Helsinki \\ e-mail: tom.moring@helsinki.fi
}

\begin{abstract}
The purpose of the present paper is to explore the dynamics of trilingual Internet use and its relation to minority language identity and acculturation among young Swedish speakers in Finland $(N=201)$ and Hungarian speakers in Transylvania $(N=388)$. Typically, a feature of linguistic minorities, trilingualism, provides speakers with the competence to move outside their original cultural realm, a feature that is rewarding at an individual level but may form a threat to the minority language culture. The results indicate in both contexts an extensive use of English alongside the minority language and a restricted amount of use of the majority language on the Internet. Majority language and English-language Internet use are strongly related to acculturation towards majority language speakers and English speakers in both contexts. Majority-language Internet use is significantly and negatively associated with minority language identity among participants in Transylvania but not among participants in Finland. Most interestingly, however, English-language Internet use is significantly and negatively related to minority language identity in both contexts. The findings and their theoretical implications are discussed.
\end{abstract}

Keywords: Hungarians in Transylvania, Swedish in Finland, Internet, English, trilingualism

1 The work of the first author was supported by a grant of the Social Science Research Council of the Society of Swedish Literature in Finland. 


\section{Introduction}

English-language Internet use has become a common phenomenon among young people in different countries and contexts (Leppänen et al. 2009, Leppänen \& Peuronen 2012, Thurlow \& Mroczek 2011). Apparently, the Internet is not the only way of disseminating the English language; however, it is one of the most influential and vibrant means. Not surprisingly, in light of the digitalization of the media and entertainment industries, more and more scholars have raised their concern about the possible negative side effects of the diffusion of English, usually pointing out the role of English in 'modern homogenizing pressures' (Edwards 2005: 471) and as a challenge for linguistic and cultural diversity (e.g. Crystal 2011, Edwards 2010, Gil 2010, Kraus 2009, Philippson \& Skutnabb-Kangas 1997).

Although the headway of English has often been discussed with respect to linguistic globalization and as a threat for linguistic diversity globally, little attention has been paid to how English may affect the survival prospects of languages at a regional level. This is of importance because regional bilingualism and multilingualism entail not only the coexistence of different languages but also discrepancies in size and power relations, which usually divide the regional linguistic landscape into minority and majority languages. Obviously, minority languages are often contested or even challenged by the surrounding majority languages, which involves that minority language speakers frequently pursue an everyday struggle for the use and, relatedly, the existence/retention of their languages. In circumstances like these, the emergence of English constitutes a special challenge. Whereas the regional majority language can be regarded as a natural and 'default' rival language for the minority languages, English enters the regional linguistic landscape as a particular third language, and as such it may be seen as an additional, a second competitive language, particularly for minority languages.

As shown by the EU language survey (Special Eurobarometer 386 2012: 15-37), language proficiency in the total population in Finland and Romania is usually limited to mother tongue plus one foreign language; $75 \%$ of the total population in Finland and $48 \%$ in Romania would be able to have a conversation in a second language. Trilingualism (mother tongue plus two languages), a typical feature of minority language speakers, is less common in the total population, $48 \%$ and $22 \%$ respectively. The numbers fall significantly when asking who would be able to communicate online in English, to 51\% in Finland and 24\% in Romania.

As we have seen in earlier research conducted in Finland, this difference in proficiency between language groups is also clearly visible in the language preference when browsing on the Internet. The Swedish minority in Finland is divided into three groups of relatively equal size, Swedish (44\%), Finnish (32\%), and English (24\%). Mother tongue speakers of the majority language 
predominantly used Finnish (92\%) and only marginally English (8\%) as their preferred language for browsing (Vincze \& Moring 2012, 2013).

Against this background, the purpose of this paper is twofold. First, we inspect the linguistic dynamics of Internet use focusing on the use of the minority language, the majority language, and English among young minority language speakers. More specifically, we aim to ascertain to which extent the different languages are used in various forms of Internet-based behaviours. Second, we will examine how the Internet use of the different languages is connected to minority language identity and acculturation. Acculturation is usually defined as a cultural and psychological change deriving from intercultural contact, that is contact with another culture (e.g. Berry 2012, Sam \& Berry 2010). As intercultural contact may take place via diverse channels, several studies revealed the importance of media use - i.e. having contact with another culture via media - in the process of acculturation (Dalisay 2012, Moon \& Park 2007, Raman \& Harwood 2008, Reece \& Palmgreen 2000, Stilling 1997, Woo \& Dominick 2003). Yet, while these studies addressed the role of media effects on acculturation into one specific cultural outgroup, the present study will compare how Internet use in the majority language and English associates with the extent to which people adopt cultural features of majority language speakers and native English speakers.

We collected data among young Swedish speakers in Finland and Hungarian speakers in Transylvania, Romania. In terms of ethnolinguistic vitality (Giles, Bourhis, and Taylor 1977), there are considerable differences between the two minority groups, that is they can be characterized by different degrees of demographic capital, status, and institutional support. In particular, Hungarian in Transylvania presents a case in which lower status and weaker institutional support are accompanied by a moderate demographic capital, whilst Swedish in Finland may be considered as a language with high status and institutional support but a lower demographic position.

\section{Method}

\subsection{Participants}

Paper-and-pencil questionnaire data was collected among students in two Hungarian schools in Transylvania $(N=388)$ and three Swedish schools in Finland $(N=201)$. The average age of the respondents was $M=16.09(S D=1.18)$ in Transylvania and $M=17.42(S D=.58)$ in Finland. In Transylvania, $47 \%$ of the respondents were males and $53 \%$ females, whereas in Finland $48 \%$ of the respondents were males and $52 \%$ females. 


\subsection{Measures}

Internet language. Participants were asked to assess the proportion (\%) of the use of the minority language, the majority language: and English in four domains representing major Internet-based behaviours, (1) browsing, (2) use of social media, (3) information seeking, and (4) interpersonal communication. The subscales were summated in such a manner that they express the total amount of the use of the three languages. The internal consistency of the summated scales was good in both regions. Specifically, in Transylvania for Hungarian Internet use, it was $\alpha=.83$, while for Romanian Internet use and English Internet use was $\alpha=.85$. Similarly, in Finland for Swedish Internet use, it was $\alpha=.82$, for Finnish Internet use $\alpha=.87$, and for English Internet use $\alpha=.84$. Detailed results about the subscales are presented in the Results section.

Minority language identity. Minority language identity was measured with three 5-point items. Participants were asked how glad and how proud they were to be a Hungarian in Transylvania and a Swedish-speaking Finn in Finland respectively. Also, they were asked how strongly they are attached to their minority language community. The scale had good reliability in both Transylvania $(\alpha=.72)$ and Finland $(\alpha=.82)$. Higher values on this scale indicate higher identification with the minority language group.

Majority language and English acculturation. Four 5-point items were used based on the psychological acculturation scale (Tropp et al. 1999) to measure acculturation into the culture of majority language speakers and into an Englishlanguage culture. The items were chosen so that they can measure comparable and meaningful aspects of acculturation. The four items were identical in both regions and also for both the majority language and English. Participants were asked to what extent they feel comfortable with the given language group; to what extent they feel they share most of their beliefs and values with the given language group; to what extend they understand people in the given language group; and to what extent they feel confident that they know how to act within the given language group. The scales had good reliability in both Transylvania (for English $\alpha=.79$, for Romanian $\alpha=.77$ ) and Finland (for Finnish $\alpha=.86$, for English $\alpha=$ .76). Higher values on this scale indicate higher levels of acculturation.

\section{Results}

\subsection{Internet Use}

A two-way within-subjects analysis of variance with language and domain as factors was performed to assess the differences in language use across the various domains among respondents in Finland. The main effect of language was 
significant, $F(2,392)=44.42, p<.001, \eta_{\mathrm{p}}{ }^{2}=.19$, but the main effect of domain was not, $F(3,588)=.68, p=.57$. The interaction term between language and domain was also significant, $F(6,1176)=134.20, p<.001, \eta_{\mathrm{p}}{ }^{2}=.41$. The pairwise comparisons indicated that the use of Swedish and the use of English varied significantly across the four domains at the level of $p<.001$. However, with respect to Finnish, the difference was significant only between browsing and social media. The results are depicted in Figure 1. Higher scores indicate more use of the given language.

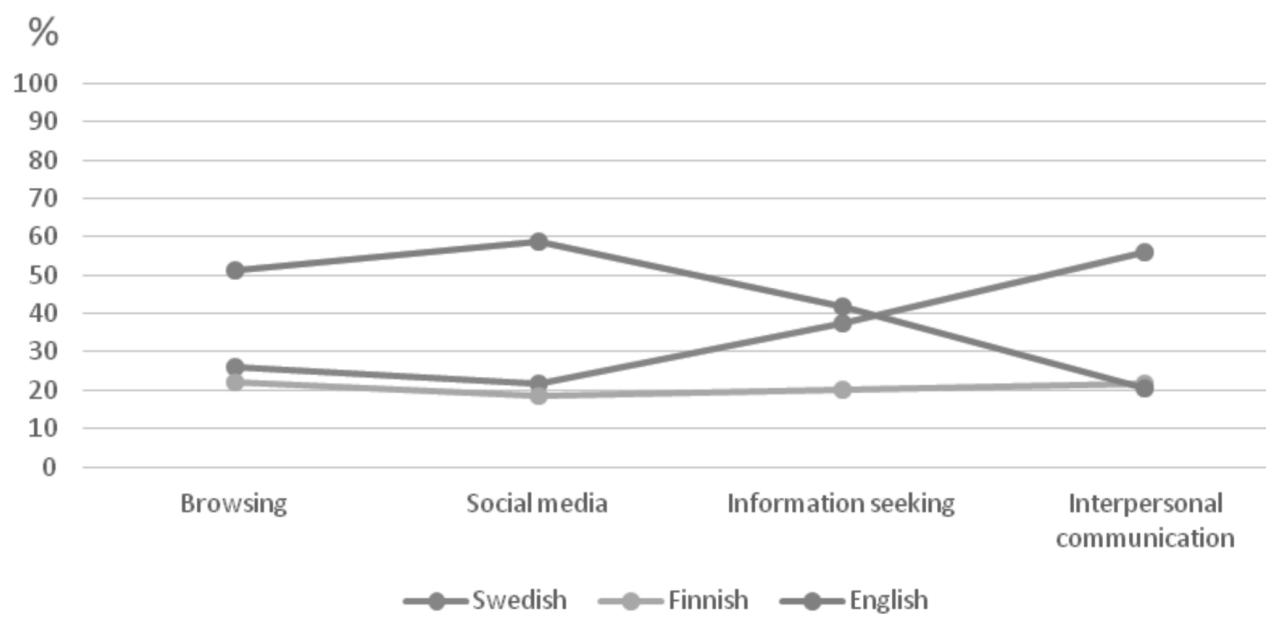

Figure 1. The use of different languages on the Internet (\%) among participants in Finland

Also, a two-way within-subjects analysis of variance with language and domain as factors was performed in Transylvania to assess the differences in language use across the various domains. The main effect of language was significant, $F(2,730)$ $=365.60, p<.001, \eta_{\mathrm{p}}{ }^{2}=.50$, but the main effect of domain was not, $F(3,1095)=.95$, $p=.42$. The interaction term between language and domain was also significant, $F(6,2190)=242.18, p<.001, \eta_{\mathrm{p}}{ }^{2}=.40$. The pairwise comparisons indicated that the use of Hungarian and the use of English varied significantly across the four domains at the level of $p<.001$. However, with respect to Romanian, it was only social media which significantly differed from browsing and interpersonal communication. The results are depicted in Figure 2. Higher scores indicate more use of the given language. 


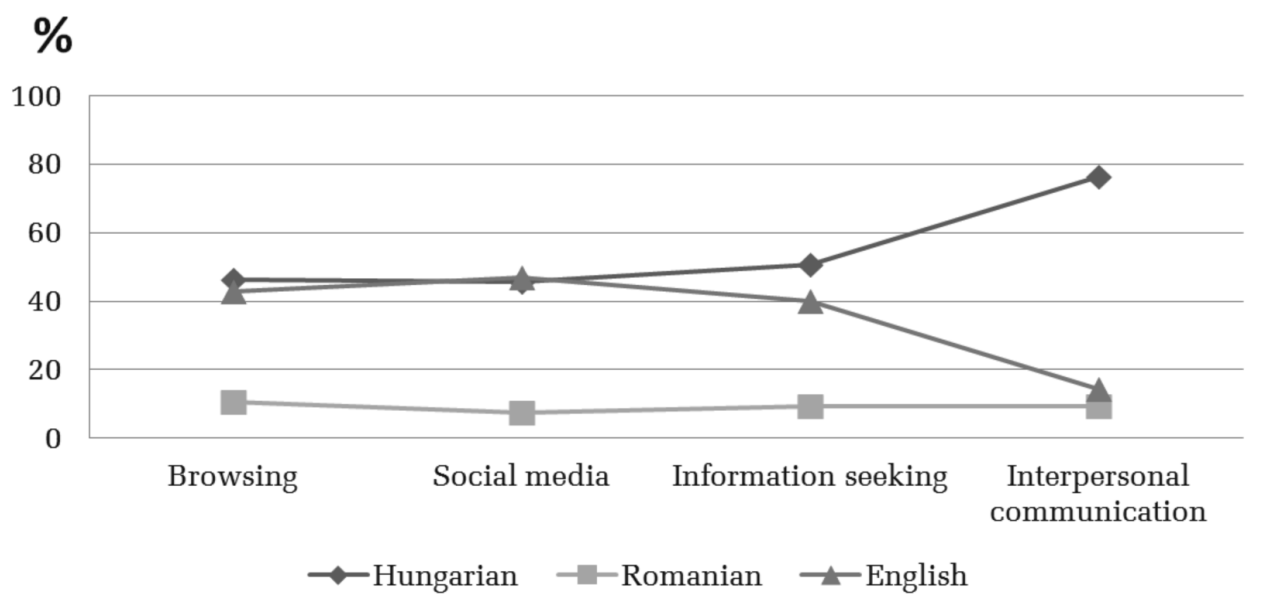

Figure 2. The use of different languages on the Internet (\%) among participants in Transylvania

From a comparative perspective, it can be seen that in regard to English the difference between the regions is most perceptible in browsing and the use of social media. Whereas in these domains participants in Finland reported a higher degree of use of English and low levels of the local languages, participants in Transylvania reported a similar amount of use of Hungarian and English and low levels of Romanian. When it comes to information seeking, there is only a slight difference between the regions; in this domain, participants use mostly their own language or English, while the use of the majority language is considerably less. Finally, with respect to interpersonal communication, it is remarkable in both regions that participants favour the use of the minority language, whereas the majority language and English are somewhat pushed back. All in all, English appears to be stronger in Internet use among participants in Finland than in Transylvania, and, noticeably, the weakest language in Internet use is the majority language, invariably in both regions.

\subsection{Minority Language Identity and Acculturation}

Mean values of the levels of minority language identity and acculturation are summarized in Figure 3. An independent-samples $t$-test indicated that participants in Transylvania $(M=4.24, S D=.86)$ identified slightly lower with the minority language than participants in Finland $(M=4.38, S D=.71), \mathrm{t}(461)$ $=-2.07, p<.05, \eta^{2}=.01$. Next, a split-plot analysis of variance with region as a between-subjects factor and acculturation (majority, English) as a within-subjects factor was performed to assess the differences in acculturation. The main effect of region was significant, $F(1,558)=385.36, p<.001, \eta^{2}=.41$. Post-hoc $t$-tests 
demonstrated higher levels of majority acculturation in Finland $(M=4.05, S D$ $=.81)$ than in Transylvania: $(M=2.88, S D=.85), \mathrm{t}(572)=-15.77, p<.01, \eta^{2}$ $=.30$. Likewise, the post-hoc comparisons indicated higher levels of English acculturation in Finland $(M=4.03, S D=.66)$ than in Transylvania: $(M=3.01$, $S D=.86), \mathrm{t}(486)=-15.79, p<.01, \eta^{2}=.34$. Neither the within-subjects effects, $F(1,558)=1.29, p=.26$, nor the interaction term, $F(1,558)=2.70, p=.10$, were significant. In other words, participants in both regions reported the same levels of majority and English acculturation.

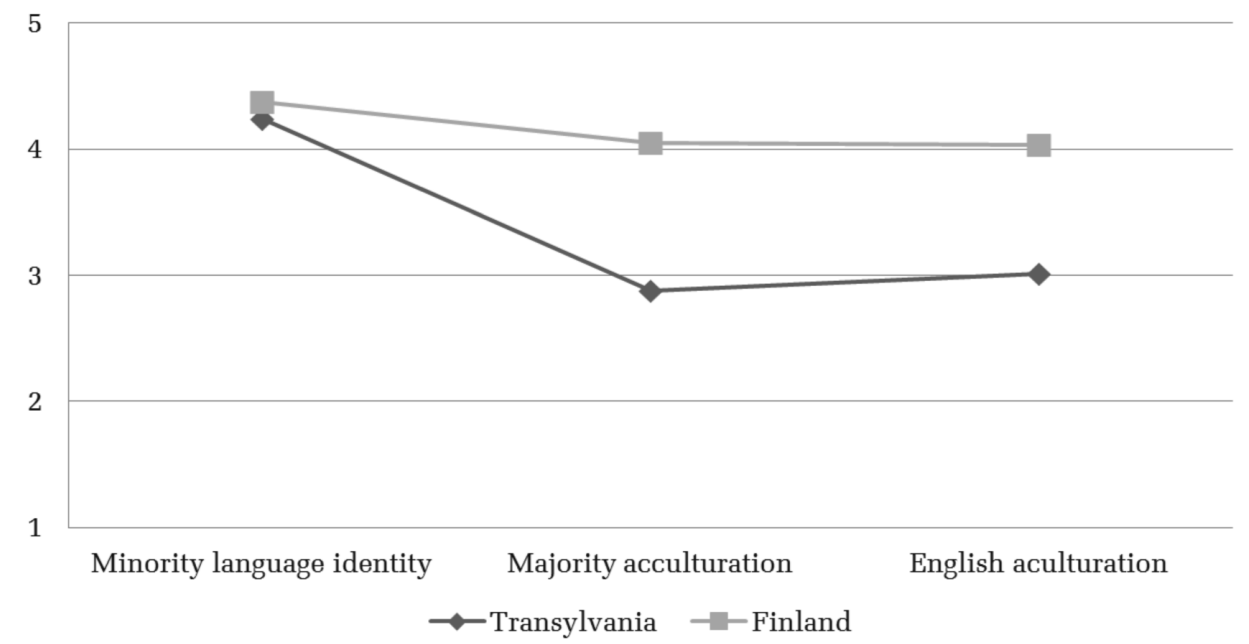

Figure 3. Mean values of minority language identity and acculturation with majority and English language

\subsection{Associations between Internet Language, Minority Language Identity, and Acculturation}

Finally, correlational analyses were conducted to check the associations between Internet language, minority language identity, and acculturation. For the sake of clarity, we report only coefficients which are of major interest.

For Finland, the results of the correlational analyses are summarized in Figure 4. As can be seen, Swedish language identity, Finnish language acculturation, and English language acculturation were significantly and positively related to Internet use in the given language. Swedish language identity was not significantly related to Finnish-language Internet use, but it was significantly and negatively related to English-language Internet use. In other words, higher levels of Internet use in English is linked to lower identification with the Swedish language. 


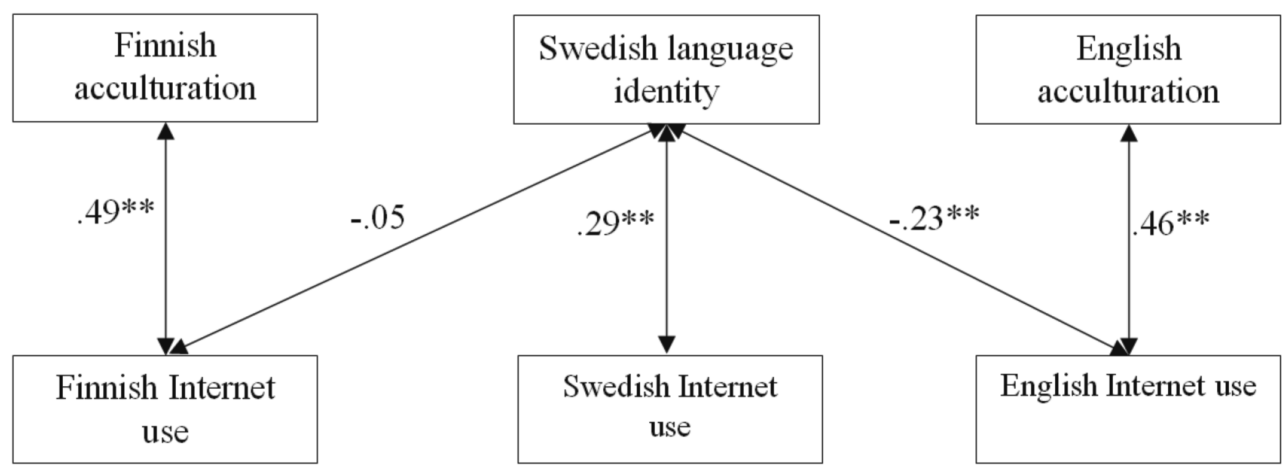

${ }^{*} \mathrm{p}<.05$

Figure 4. Correlations coefficients

$* * \mathrm{p}<.01$

For Transylvania, the results of the correlational analyses are summarized in Figure 5. As can be seen, Hungarian language identity, Romanian language acculturation, and English language acculturation were significantly and positively related to Internet use in the given language. Hungarian language identity was significantly and negatively related to both Romanian-language and English-language Internet use. That is, higher levels of Internet use in English or Romanian are linked to lower identification with the Hungarian language.

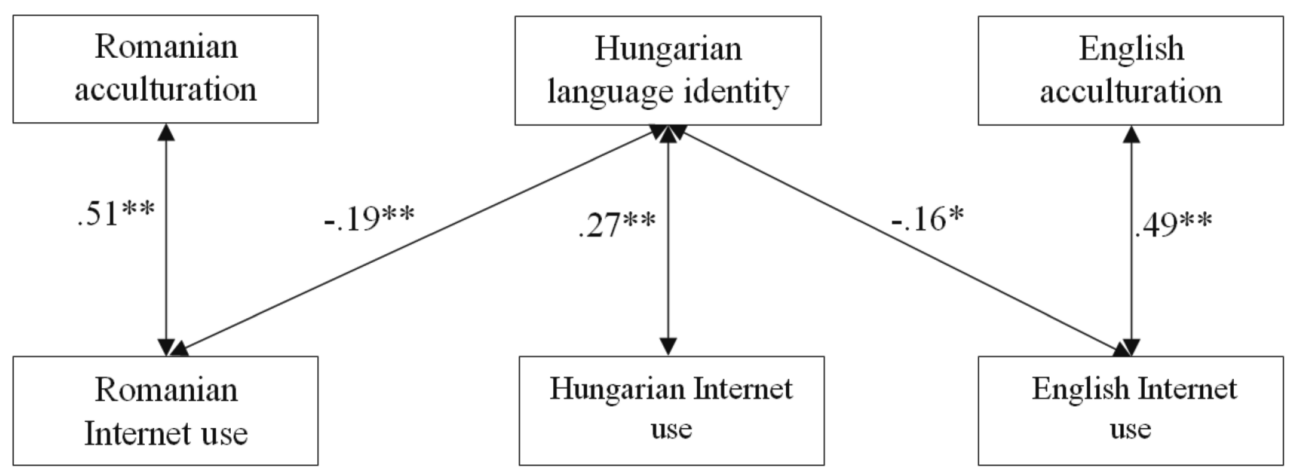

$* \mathrm{p}<.05$

Figure 5. Correlations coefficients

$* * \mathrm{p}<.01$ 


\section{Discussion}

The purpose of the present paper is to shed some light on the dynamics of trilingual Internet use and its relation to minority language identity and acculturation among young Swedish speakers in Finland and Hungarian speakers in Transylvania.

In line with earlier studies (Vincze 2012, Vincze \& Moring 2012), the results demonstrated the extensive use of English on the Internet in both research contexts. Moreover, and somewhat surprisingly, it was also shown that English actually appears to pose a greater challenge for the use of the minority language in both regions than the local majority languages do. Indeed, while participants in Finland as well as Transylvania mostly favour the local minority language and English when using the Internet, the local majority languages seem to 'retreat to the margins' in Internet use.

Next, correlational analyses indicated strong relationships between online language use in English as well as in Finnish and acculturation towards the respective language-related cultures. That is, more use of the majority language and English on the Internet is connected to higher levels of acculturation in each language group. This finding is consistent with earlier studies (see e.g. Dalisay 2012, Moon \& Park 2007, Raman \& Harwood 2008, Reece \& Palmgreen 2000, Stilling 1997, Vincze \& Gasiorek 2016, Woo \& Dominick 2003). This highlights the prominent role of media use in acculturative processes. However, it is vital to note that studies have seldom addressed the media-acculturation link from the perspective of a third language.

Results also indicated that majority-language Internet use was significantly and negatively associated with minority-language identity among participants in Transylvania, but this relationship was not statistically significant among participants in Finland. One potential explanation for this inconsistent finding may be related to the demographical differences between the two research contexts. Indeed, whereas most of our Transylvanian participants are coming from Hungarian-dominated municipalities, where real-life contact with Romanian speakers is limited, our participants in Finland live in municipalities which are populated mostly by Finnish speakers providing frequent contact with the Finnish language and culture in everyday life. Consequently, while majority-language Internet use may deviate considerably from the everyday cultural experiences of our Hungarian-speaking participants, majority-language Internet use just 'fits' everyday cultural experiences of our Swedish-speaking participants. That said, the Internet cannot be seen as a major source of Finnish-oriented acculturation among our Swedish-speaking participants; rather, Finnish-oriented acculturative processes take place through real-life contact with Finnish speakers in the surrounding local environment. 
Undoubtedly, our most striking finding is related to the association between English-language Internet use and minority language identity. As it was demonstrated invariably in both regions, English-language Internet use was meaningfully and negatively related to minority language identity. Although the effect sizes suggest weak relationships, this finding is of special importance as it is consistent across the two research contexts. Indeed, to our knowledge, no other studies have revealed this pattern among minority-language speakers yet.

The implications of these results are manifold and to some extent paradoxical for the sustainability of the minority language community. As has been noted elsewhere (Lambertz \& Mukhametshin 2010), the trilingual competence of the minority community is an asset for the individual speaker who can often gain from these skills not only culturally but also professionally and economically. However, at an aggregate level, these skills may form a threat towards the sustainability of the linguistic community, particularly in situations where the minority language offers lesser opportunities than the majority language - as we can see from our results, particularly English may form a threat here (Kornai 2013; Moring, forthcoming 2017).

These risks, which in the first phase form a threat to the trilingual minority language community, would be, in a longer perspective, counterproductive to the interests of the countries where minorities reside as the benefits from language proficiency would disappear. At the same time, the individual benefits experienced by the minority-language speakers may also lead to a migration of majority-language speakers towards the minority community. This process has been observed, for example, in Finland, where bilingual families with one Finnish parent and one Swedish parent predominantly (65\%) tend to register the Swedish minority language as mother tongue for their children (Finnäs 2013: 23). However, irrespective of this surplus in the form of registered mother tongue speakers among children, the gross figures for the Swedish minority language community have shown a tendency to shrink due to a higher level of migration among Swedish speakers. Between 2000 and 2015, almost 10\% of the Swedish population in Finland migrated, mainly to Sweden (Kepsu 2016: 4). Thus, the net balance of these processes for the size of the language remains between neutral and slightly negative. Clearly, the study at hand requires further research to validate the findings and to probe deeper into a discussion about their consequences. Among the limitations and shortcomings, for one thing, the findings presented here are based on cross-sectional data. This does not allow for the ascertainment of causality or its direction. This caveat should be kept in mind when inferring the relationships between the concepts used in the study such as minority language identity and Internet language. Also, it is necessary to emphasize that by referring to English we focused merely on the language of Internet use and ignored the cultural content of Internet use. This, in fact, impedes us to draw 
unambiguous conclusions about the cultural implications of online behaviour. More particularly, while our focus was on the levels of acculturation in the group of native English speakers, it is highly likely that the greatest part of Englishlanguage Internet use does not have such a straightforward cultural direction and does not imply contact with native English speakers and the Anglo-American culture. Apparently, one should also consider other cultural concomitants of English-language Internet use, most importantly the development of international identities and internationalization, i.e. using English without being connected to any specific cultural group.

The scope of the present study opens several paths for further research. An obvious corollary would be the investigation of the relevance and bearings of English-language Internet use among other linguistic minorities. Also, future research should thoroughly examine the potential linguistic, cultural, and psychological antecedents and consequences of English-language Internet use by means of comprehensive conceptual models. Additionally and importantly, a particularly fruitful avenue for future work could be conducting longitudinal studies to inspect the possible impacts of Internet use on the retention of minority languages at individual as well as aggregate levels. This type of research could also be informative with respect to policies that societies may consider in order to maintain and further enhance trilingualism as a cultural and economic asset.

\section{References}

BERRY, John W. 2012. Acculturation. In:Helmut, K. Anheier-Mark, Juergensmeyer (eds), Encyclopedia of Global Studies. Thousand Oaks, CA: Sage. 16-18.

DALISAY, Francis. 2012. Media Use and Acculturation of New Immigrants in the United States. Communication Research Reports 29(2): 148-160.

EDWARDS, John. 2005. Language Minorities. In: Davies, Alan-Elder, Catherine (eds), The Handbook of Applied Linguistics. Oxford: Blackwell. 451-475.

2010. Minority Languages and Group Identity: Cases and Categories. John Benjamins Publishing.

FINNÄS, Fjalar. 2013. Finlandssvenskarna 2012.En statistisk rapport. Helsingfors: The Swedish Assembly of Finland.

GIL, Jeffrey. 2010. The Double Danger of English as a Global Language. English Today 26(1): 51-56.

KRAUS, Peter A. 2009. A Union of Diversity: Language, Identity and PolityBuilding in Europe. New York: Cambridge University Press.

LAMBERTZ, Karl-Heinz-FARID, Mukhametshin. 2010. Minority Languages - an Asset for Regional Development. Chamber of Regions CPR (18)3. Strasbourg: Council of Europe [Congress of Local and Regional Authorities]. 
LEPPÄNEN, Sirpa-PEURONEN, Saija. 2013. Multilingualism and the Internet. In: Carol A. Chapelle (ed.), The Encyclopedia of Applied Linguistics. Oxford, UK: Wiley-Blackwell.

LEPPÄNEN, Sirpa-PITKÄNEN-HUHTA, Anne-PIIRAINEN-MARSH, ArjaNIKULA, Tarja-PEURONEN, Saija. 2009. Young People's Translocal New Media Uses: a Multiperspective Analysis of Language Choice and Heteroglossia. Journal of Computer-Mediated Communication 14(4): 1080-1107.

KEPSU, Kaisa. 2016. Hjärnflykt eller inte. En analys av den svenskspråkiga flyttningen mellan Finland och Sverige 2000-2015. Magma pamflett 2/2016. Helsingfors: Think Tank Magma.

KORNAI, A. 2013. Digital Language Death. PLoS ONE 8(10): e77056.

MOON, Seung-jun-YI PARK, Cheong. 2007. Media Effects on Acculturation and Biculturalism: a Case Study of Korean Immigrants in Los Angeles’ Koreatown. Mass Communication and Society 10(3): 319-343.

MORING, Tom. 2017 (under review). Minority Language Media and Journalism. Policies, Issues of Power and Citizenship, Finance and Organization.

REECE, Debra-PALMGREEN, Philip. 2000. Coming to America: Need for Acculturation and Media Use Motives among Indian Sojourners in the US. International Journal of Intercultural Relations 24(6): 807-824.

SAM, David L.-BERRY, John W. 2010. Acculturation When Individuals and Groups of Different Cultural Backgrounds Meet. Perspectives on Psychological Science 5(4): 472-481.

SPECIAL EUROBAROMETER 386. 2012. Europeans and Their Languages. Brussels: European Commission, DG Comm. Research and Speechwriting Unit. STILLING, Erik A. 1997. The Electronic Melting Pot Hypothesis: the Cultivation of Acculturation among Hispanics through Television Viewing. The Howard Journal of Communication 8(1): 77-100.

THURLOW, Crispin-MROCZEK, Kristine. 2011. Digital Discourse: Language in the New Media. Oxford University Press.

TROPP, Linda R.-ERKUT, Sumru-GARCÍA COLL, Cynthia-ALARCÓN, Odette-VÁZQUEZ GARCÍA, Heidie A. 1999. Psychological Acculturation: Development of a New Measure for Puerto Ricans on the U.S. Mainland. Educational and Psychological Measurement 59: 351-367.

WOO, Hyung-Jin-DOMINICK, Joseph R. 2003. Acculturation, Cultivation, and Daytime TV Talk Shows. Journalism and Mass Communication Quarterly 80(1): 109-127.

VINCZE, László. 2012. Language Minorities and New Media: Facing Trilingualism? In: Åkermark, Sia-Bloed, Arie-Hofmann, Rainer-Marko, Joseph-Mayall, James-Packer, John-Weller, Marc (eds), European Yearbook of Minority Issues 9: 355-366. Leiden/Boston: Martinus Nijhoff Publishers. 
VINCZE, László-MORING, Tom. 2012. Swedish in Finland: Pushed Back in the cyberspace? Journal of Ethnopolitics and Minority Issues in Europe 11(2): $25-37$.

2013. Towards Ethnolinguistic Identity Gratifications. In: Gruffydd Jones, Elin Haf-Uribe-Jongbloed, Enrique (eds), Minority Languages and Social Media: Participation, Policy and Perspectives. Clevedon: Multilingual Matters. 47-57. 